\title{
ANÁLISE E DESCRIÇÃO DA FONOLOGIA SEGMENTAL DO MANXINERU
}

\section{ANALYSIS AND DESCRIPTION OF THE MANXINERU SEGMENTAL PHONOLOGY}

Fábio Pereira Couto

Universidade Federal de Rondônia, UNIR, Ji-Paraná, RO, Brasil

\begin{abstract}
Resumo: Neste artigo apresentamos a descrição da língua Manxineru, variedade da língua Yine (família Aruák), falada no sudeste do Estado do Acre, Brasil. Este trabalho foi pensado e elaborado não só como forma de descrever e divulgar a minha pesquisa desenvolvida em dissertação de mestrado em 2012 e ampliada em tese de doutorado em andamento, mas também com a intenção de contribuir para os estudos de línguas e para conhecimento da língua Manxineru. A descrição fonológica feita nesta pesquisa foi desenvolvida sob o viés da fonética articulatória e em uma perspectiva fonológica, considerando princípios de análise fonêmica, que tem, como orientaçáo fundamental, a distribuiçáa dos sons em sequências sonoras mais largas, tais quais sílabas e palavras.
\end{abstract}

Palavras-chave: Fonologia; Fonética; Manxineru; Família Aruák.

Abstract: In this article we present a description of Manxineru language, variety Yine language (Arawak family) spoken in the southeastern state of Acre (Brazil). This work was planned and executed in order to describe and disseminate my research conducted on master"s dissertation in 2012 and expanded in doctoral thesis in progress. The phonological description made in this article intends to contribute to the study of languages and knowledge of Manxineru language. This research was developed under the bias of phonetic articulation and phonological perspective, considering principles of phonemic analysis, is fundamental orientation distribution of the sounds in wider sound sequences such that syllables and words.

Keywords: Phonology; Phonetics; Manxineru; Arawak Family.

\section{Introduçáo}

O foco deste trabalho é a descrição fonológica do Manxineru, (ISO 639: mpd), língua pertencente à família Aruák, constituída de outras 43 línguas, das quais 19 são faladas no território brasileiro (RODRIGUES, 2002; RAMIREZ, 2001). A língua Manxineru é falada pelo povo conhecido no Brasil pelo mesmo nome, Manxineru, e se caracteriza por ser

\footnotetext{
${ }^{1}$ Adotamos o item lexical MANXINERU para nos referir ao povo e à língua dos Manxineru, por ser uma escrita mais aceita pelos povos indígenas nativos Manxineru, apesar da existência de outras grafias: Manxineri, Manchineri ou até Piro (esta usada no Peru).
} 


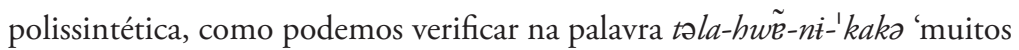
sapos de chifre' ou ainda em no-matfira' tene 'meus macacos pretos', fato esse que torna a análise fonológica ainda mais complexa e rica.

Destacamos aqui os inventários de fonemas consonantais e vocálicos, seguidos de exemplos de pares mínimos e análogos que ilustram contrastes entre sons que compartilham propriedades fonéticas e que poderiam levantar suspeitas de serem realizaçóes das mesmas entidades fonológicas. Estes são alguns dos resultados do estudo fonético e fonológico que estamos desenvolvendo sobre a língua Manxineru, desde 2010, vinculado a dois projetos de pesquisa do Laboratório de Línguas e Literaturas Indígenas da Universidade de Brasília (doravante LALLI): "Parentesco, Comparação, Mudanças Linguísticas, Variação, Dialetologia e Contato Linguístico" e "Ensino de Línguas Indígenas Brasileiras e Formação Superior de Professores Pesquisadores Indígenas".

$\mathrm{Na}$ metodologia adotada para o trabalho de campo, tem tido importância fundamental a participação dos professores e dos pesquisadores indígenas na coleta, discussão, análise e aplicação dos dados. Assim, a coleta de material tem sido planejada e realizada em equipe, privilegiando entrevistas, gravaçóes em diferentes discursos individuais ou em grupos. A transcrição de dados tem sido feita igualmente em conjunto e com a participação dos falantes.

Ressaltamos que parte significativa dos dados para a pesquisa foi coletada durante três pesquisas de campo feitas em parceria com três colaboradores indígenas: uma mulher, Mariana Souza Samarra Manchineri (25 anos), e dois homens, Leudo Artur Brasil Manchineri (18 anos) e Lucas Artur Brasil Manchinery (32 anos). Todos esses colaboradores são falantes bilíngues (Manxineru-Português), com um bom domínio da Língua Portuguesa. Essa geração de dados teve a orientação da Professora Dra. Ana Suelly Câmara Cabral e do Professor Dr. Aryon Dall'Igna Rodrigues, em julho de 2011, janeiro e julho de 2012, no estado do Acre. Também fizemos mais três gravaçóes no LALLI/UnB em mais três oportunidades: março e novembro de 2012 e, por último, em setembro de 2014. Esta última, com o propósito para formar o corpus específico para análise acústica.

A partir de uma perspectiva fonética articulatória, observamos detalhes da articulação dos sons no aparelho fonador, sendo que, para isso, foram necessárias referências tais como Pike ([1947] 1971), Ladefoged e Maddieson (1993); consoante com uma perspectiva fonológica, foi essencial a consideração de princípios de análise fonêmica, que considera como fundamental a distribuição dos sons em sequências sonoras mais 
largas, tais quais sílabas e palavras. Partimos do princípio de que os sons são modificáveis pelo ambiente e que são fonemicamente distintos, se provado que não são simplesmente modificaçóes causadas pelo ambiente em que ocorrem. Assim, contrastes em posiçóes idênticas em mesmo ambiente ou em ambientes análogos foram testes para a análise das unidades sonoras como fonêmicas ou não (TRUBETZKOY, [1939] 1976; PIKE, [1947] 1971). Para a análise, a descrição e a caracterização dos fonemas nos servimos também de Clements e Hume (1995). Os trabalhos descritivos sobre a Fonética e Fonologia ou sobre línguas Aruák que serviram de referências para este artigo foram Couto (2012), Matteson (1965), Hanson (2010), Rodrigues (2002, 2003), Aikhenvald (1999), Ramirez (2001) e Facundes (2000), dentre outros.

O presente artigo está organizado em 4 (quatro) seçôes e suas respectivas subseçôes: na seção 1 , tem-se a introdução; na seção 2 , descrevemos os fonemas da língua com os respectivos inventários fonológicos; na seção 3, elaboramos breve descrição sobre as adaptaçōes fonológicas pelo Manxineru de empréstimos do Português; na seção 4, apresentamos as considerações finais.

\section{Os Fonemas da Língua Manxineru}

Com base nos dados analisados da língua Manxineru, depreendemos e descrevemos 16 fonemas para formularmos o sistema consonantal do Manxineru - /p/, /t/, /k/, /ts/, / $/ \mathrm{f} /, / \mathrm{cç//s/,/ç//S/,} \mathrm{/h/,} \mathrm{/m/,} \mathrm{/n/,} \mathrm{/s/,} \mathrm{/l/,} \mathrm{/w/,}$ /j/ - e cinco fonemas vocálicos - /i/, /e/, /i/, /a/, /o/, como se pode observar nas tabelas 1 e 2 . Acerca das realizaçóes fonéticas dos fonemas consonantais, observa-se que fonemas se distinguem em seis pontos de articulação - labial, alveolar, alveopalatal, palatal, velar e glotálico - e seis modos de articulação - oclusivo, africado, fricativo, nasal, líquido, aproximante; já a realização dos fonemas vocálicos distinguem dois graus de altura da língua, +alto e -alto, duas distinçôes de avanço/recuo da língua +anterior e -anterior, e arredondamento dos lábios, +arredondado e -arredondado. Para detalhes de agrupamento por traços naturais, ver tabelas 1 e 2 .

\subsection{Inventário fonológico das consoantes}

$\mathrm{Na}$ tabela 1, podemos verificar a representação dos 16 fonemas consonantais do Manxineru. 
Tabela 1 - Inventário fonológico das consoantes do Manxineru

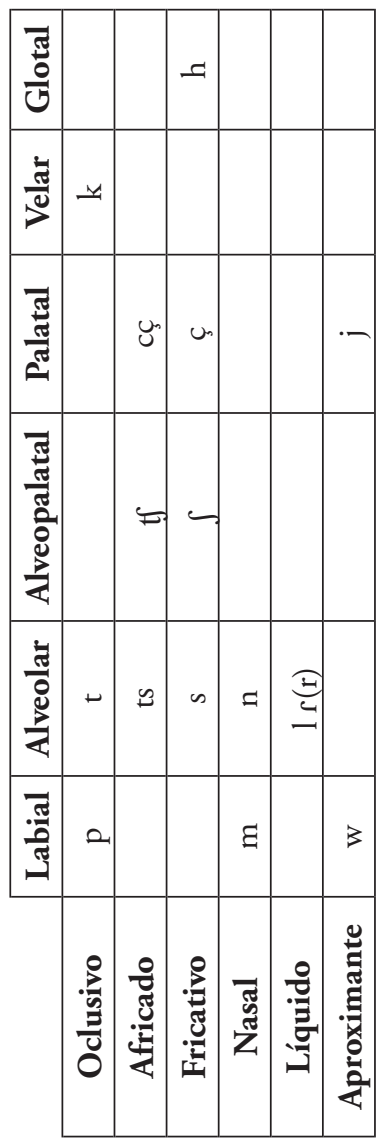

Fonte: Couto (2012)

O nosso quadro fonológico diferencia-se de outros trabalhos sobre a fonologia do complexo Yine-Piro-Manxineru, pois Matteson (1965) descreve consoantes nasais e aproximantes longas /m:, ni, y:(j), w:/, enquanto nós não identificamos, até o presente, essas consoantes longas com valor distintivo, assim como não identificamos a existência de uma africada /tx (tç)/, proposta por essa mesma autora. Também, diferentemente de Rebecca Hanson (2010), náo descrevemos uma fricativa glotal nasal /h/, 
nem uma oclusiva palatal /c/ para a variante Piro; finalmente, distintamente de Silva (2013), consideramos a existência de um fonema /1/ e um fonema /ç/ para a variante Manxinru.

Em nossa pesquisa, descrevemos, para o Manxineru, 5 fonemas vocálicos orais, considerando que esses sofrem processo de nasalização em ambientes propícios.

\section{Demonstrando Contrastes}

Nesta seção, demonstramos, por meio de pares mínimos e/ou análogos, contrastes que fundamentam a existência de dezesseis fonemas consonantais e cinco fonemas vocálicos em Manxineru.

\subsection{Contrastes entre Fonemas consonantais}

Descrevemos, para o Manxineru, seis (6) consoantes obstruentes descontínuas, sendo que as oclusivas se distinguem em três pontos de articulaçáo: labial /p/, alveolar/t/ e a vela / $/$; as africadas se distinguem em: alveolar/ts/, alveolpalatal /t $\mathrm{t} /$ e palatal /cç/.

(1)
a. ['çep't ti i]
/çepitfi/
'piolho'
$/ \mathrm{p} / \mathrm{vs} . / \mathrm{w} /$
b. ['mati]
/çewtfi/
'pulga'
['pati]
/mati/
'sabiá'
$/ \mathrm{p} / \mathrm{vs} . / \mathrm{m} /$
/pati/
'pai'

(2) a. [kapa'teri $]$

/kapaterì/

'pessoa vergonhosa'

/t/ vs. /1/

[kihi'leri]

/kihileri/

'ele é feliz', 'feliz'

b. [ko'tfiro]

/kotfiro/

'faca'

/t/ vs. /s/

[ma'tfito]

/matfito/

'facão'

(3)

\begin{tabular}{|c|c|c|c|}
\hline a. ['hitfa] & /hitfa/ & 'vocês' & $/ \mathrm{t} \int /$ vs. $/ \mathrm{t} /$ \\
\hline ['hitta] & /hita/ & 'eu' & \\
\hline b. [']içi] & / içi/ & 'milho' & $/ \mathrm{t} / \mathrm{vs} . / \int$ \\
\hline ['tfiçi] & /t $\int \mathrm{içi} /$ & 'terra' & \\
\hline c. [ku'tsiutfi] & /kotsit $5 \mathrm{i} /$ & $\begin{array}{l}\text { 'veia' } \\
\text { 'fogo' }\end{array}$ & $/ \mathrm{t} /$ vs. $/$ ts $/$ \\
\hline 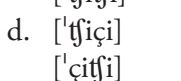 & $\begin{array}{l}/ \mathrm{f} \mathrm{fiçi} / \\
/ \text { cit } \mathrm{i} /\end{array}$ & $\begin{array}{l}\text { 'terra' } \\
\text { 'pé' }\end{array}$ & $/ \mathrm{t} /$ vs. /ç/ \\
\hline
\end{tabular}


(4)
a. ['hĩçri]
/hiçiri/
'bico'
/cç/ vs. /ç/
[kisa'cçeri]
/kisacçeri/
'traíra'
b. [çitfa'peli]
/çitfapalì/
'tatu canastra'
/sitfo/
'mulher'
/ç/ vs. /s/
['sitfu]

(5)
a. ['tsapi]
/tsapi/
'timbó'
/ts/ vs. /h/ [salu'hapi]
/salohapi/
'remo'
b. ['tsapi]
/tsapi/
'agulha'
/ts/ vs. /s/
['sati]
/satí/
'um' (1)

(6)
a. [çi'mekv]
/çimeka/
'mandioca'
/ç/ vs. /cç/
[,cçijo'çiri]
/cçijoçri/
'jacaré'
/çepitfi/
'orelha'
/Sepitfi/
'piolho'
/ç/ vs. /S/
[' $\left.\int \varepsilon p^{h} t f i\right]$

(7)
a. [nnẽmika'hĩnte] [na, si'kẽnte]

/namikahinta/

'eu dormi'

/h/ vs. /k/

/nasikənta/

'eu estou correndo'

b. ['hiี่วิ]

/hiha/

'piláo'

'mata'

['hõfa]

/hosal

'arara'

c. ['picçi]

/picçi/

'cuia'

/h/ vs. /S/

['pafĩo]

/paho/

'tatu canastra'

'mulher'

/ç/ vs. /s/

['sitfu]

/çitfapali/

/sitfo/

'orelha'

/S/ vs. /ç/

['septri]

/çepitfi/

'piolho'

/h/vs. /cç/

/Sepitfi/

'ele está mastigando'

$/ \mathrm{t} /$ vs. / $\mathbf{k} /$

[rasi"kate]

/ramotfata/

'ele morde'

(11)
a. [kahin'mali]
['wale]
b. [ $\mathrm{t}^{\circ}, \mathrm{kat}$ ü' nale] [,kasa'malì]

/rajikata/

'som'

$/ \mathrm{m} / \mathrm{vs.} / \mathrm{w} /$

/kahimali/

'ele'

/tokatfonale/

'ariranha'

/m/ vs. /n/

(12)
a. [katfi'noli]
b. [pi'natfi]
['satfi]
/katfinoli/
'dor'
[kamo'tolv]
/kamotolo/
'abelha arapuâ'
/pinatfi/
'ânus de você'
/satfi/
'barriga'
/n/ vs. /t /
/kotsitfi/
'veia'
/kajati/
'paca'
[ka'jati]
/kajati/
'paca'
/niokanati/ 'eu mando'
/n/ vs. /s/
b. [ka'jati] [nioka'nati]
/j/ vs. /ts/
/j/ vs./n/ 
(14)
a. [ra' $\mathrm{fitfa}]$
/rasitfa/
'cérebro dele'
/r/ vs. /n/
[na'sitfa]
/nasitfa/
'meu cérebro'
b. [ko'tfiro]
/kotfiro/
'faca'
/f/ vs. /t/
[ma'tsito]
/matfito/
'facão'

(15)
a. [kapa'terì]
[kihi'leri]
/kapaterí/
'pessoa vergonhosa'
/l/ vs. /t/
/kihilerí/
'ele é feliz', 'feliz', 'coisa boa'
b. [pa'nere]
/panere/
'tribo'
/1/ vs. /n/
[kihi'lerì]
/kihilerí/
'ele é feliz', 'feliz', 'coisa boa'
c. [pra'tfi)ne]
/paratfine/
'teu animal de estimação' /// vs. /r/
[ipla'tsoli]
/palatsoì/
'martim pescador'

Cabe destacar que a fricativa glotal / h/ apresenta um grau importante de variação com motivação especial e que contribui para a nasalização vocálica na língua. A variação [h] dá-se ao ocorrer intervocalicamente, quando se realiza vozeada, ao mesmo tempo nasalizando as vogais adjacentes. Exemplo disso é ['hõ i]. Já o alofone [h] ocorre nos demais ambientes, mas é igualmente fonte de nasalidade para vogais seguintes. Nossa análise se distingue das propostas de Matteson (1965), Sebastián (2006), e Rebecca Hanson (2010), pois, para esses autores, há um fonema nasal $/ \hbar /$ no dialeto Piro, que teria um alofone [ç] (cf. seção 2.3.10).

\subsection{Contrastes entre Fonemas Vocálicos}

Descrevemos cinco (5) fonemas vocálicos para o Manxineru: /i/ [+alto, +anterior] /í/ [+ alta -anterior], /o/ [+alta -anterior, +arredondado] le/ [-alto +anterior] e /a/ [-alto, -anterior].

\begin{tabular}{|c|c|c|c|}
\hline ['çeçi] & / Seçi/ & 'homem' & /i/ vs. /e/ \\
\hline ['Siçi] & / içi/ & 'milho' & \\
\hline ['tsapi] & /tsapi/ & 'timbó' & /ì/ vs. /ì / \\
\hline ['tsapì] & /tsapí/ & 'agulha' & \\
\hline [hi'pata] & /hipata/ & 'casca' & lé/ vs. /a/ \\
\hline [hi'pire] & /hipile/ & 'galho' & \\
\hline ['pitit] & /pittíl & 'vagalume' & /ił/ vs. /o/ \\
\hline ['potí] & /poti/ & 'vários' & \\
\hline ['wale] & /wale/ & 'ele' & /a/ vs. /e/ \\
\hline ['wale] & /wala/ & 'ela' & \\
\hline
\end{tabular}


(21)

/haso/

'morcego'

/o/ vs. /a/

['hõ $\left.\int \mathrm{e}\right]$

/hofe/

'mata'

\subsection{Particularidades Alofônicas das Consoantes}

Nesta seção, descrevemos os ambientes de ocorrência dos alofones dos fonemas consonantais do Manxineru.

\subsubsection{O Fonema $/ \mathrm{p} /$}

O fonema fricativo alveolar surdo /p/ possui um único fone [p], que ocorre em posição de onset. Exemplos:

Em posição de onset em sílaba inicial:

(22) [pi'fĩ̃me] 'você tropeçou'

Em posição de onset em sílaba medial:

(23) [i,oçi'pẽne] /ioçipanal 'emborcado'

Em posição de onset em sílaba final:

(24) [hï $\int$ atu'kape $]$ /hifatokape/ 'ele segurou algo' (algo que caiu)

\subsubsection{O Fonema $/ \mathrm{t} /$}

O fonema fricativo alveolar surdo / $\mathrm{t} /$ possui um único fone $[\mathrm{t}]$, que ocorre em posição de onset. Exemplos:

Em posição de onset em sílaba inicial:

(25) [ti'çire] /tiçira/ 'aquele'

Em posição de onset em sílaba medial:

(26) [his'take] /histaka/ 'ele cortou'

Em posição de onset em sílaba final:

(27) ['powte] '/potel 'vários' 


\subsubsection{O Fonema $/ \mathrm{k} /$}

O fonema fricativo alveolar surdo $/ \mathrm{k} /$ possui um único fone $[\mathrm{k}]$, que ocorre em posição de onset. Exemplos:

Em posição de onset em sílaba inicial:

(28) [ko'pire] /kopirel 'no meio (do caminho'

Em posição de onset em sílaba medial:

(29) [is'kite] /riskita/ 'gancho'

Em posição de onset em sílaba final:

(30) ['pike] '/pikal 'só, 'sozinho'

\subsubsection{O Fonema /ts/}

O fonema fricativo alveolar surdo /ts/ possui um único fone [ts], que ocorre em posição de onset. Exemplos:

Em posição de onset em sílaba inicial:

(31) ['tsũ:mi] /tsomi/ 'berne'

Em posição de onset em sílaba medial:

(32) [ma'tsawa] /matsawal 'cego'

Em posição de onset em sílaba final:

(33) [,noçi'witse] /noçiwitsa/ 'meu cabelo'

\subsubsection{O Fonema $/ \mathrm{t} /$}

O fonema fricativo alveolar surdo $/ \mathfrak{t} /$ possui um único fone $[\mathrm{t}]$, que ocorre em posição de onset. Exemplos:

Em posição de onset em sílaba inicial:

(34) ['tfinu $] \quad / \mathrm{f}$ ino/ 'dor' 
Em posição de onset em sílaba medial:

(35) [pi'tf̌̃ne $] \quad /$ pitfana/ 'seu'

Em posição de onset em sílaba final:

(36) $\quad\left[k^{\prime}\right.$ tatfi $] \quad / k o t a t 5 i / \quad$ 'queixo'

\subsubsection{O Fonema $/ s /$}

O fonema fricativo alveolar surdo /s/ possui um único fone [s], que ocorre em posiçấo de onset e em posição de coda, mas nunca em final de palavra. Exemplos:

Em posição de onset em sílaba inicial:

(37) ['sotili] Isotilit/ 'pedra'

Em posição de onset em sílaba medial:

(38) [ra'sike $] \quad$ /rasika/ 'ele corre'

Em posição de onset em sílaba final:

(39) ['muse $] \quad$ /mosal 'coruja', 'caboré'

Em posição de coda de sílaba inicial:

(40) [kas'pike] /kaspika/ 'soltar'

Em posição de coda em sílaba medial:

(41) [noki'sistfi] /nokisistfi/ 'minha perna'

\subsubsection{O Fonema $/ \int /$}

O fonema fricativo alveopalatal surdo / / / possui um único fone [S], que ocorre na posiçáo de onset e na posiçáo de coda, mas nunca ocorre seguindo a vogal /ił/. Exemplos:

Em posição de onset em sílaba inicial:

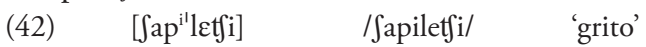


Em posição de onset em sílaba medial:
(43)
[ra'sitfa]
/rasitfa/
'cérebro' 'cérebro dele'

Em posição de onset em sílaba final:

(44) ['hr̃es $] \quad / h a j o / \quad$ 'morcego'

Em posição de coda em sílaba inicial:

(45) ['hajke] /rafka/ 'ele morde'

Em posição de coda em sílaba medial:

(46) [p'ko'laftgi] /pikolastfi/ 'queixo de você'

\subsubsection{O Fonema /cç/}

O fonema /cç/ possui um único fone [cç], que ocorre na posição de onset e sempre diante de /i/ ou /e/. Não ocorre em sílaba final. Exemplos:

Em posição de onset em sílaba inicial:

(47) [,cçi'joçri] /cçijoçiri/ 'jacaré’

Em posição de onset em sílaba medial:

(48) [kisa'cçeri] /kisacçeri/ 'traíra'

\subsubsection{O Fonema /ç/}

O fonema /ç/ possui um único fone [ç], que ocorre na posição de onset, sempre diante de /i/ ou /e/, e na posição de coda. Exemplos:

Em posição de onset em sílaba inicial:

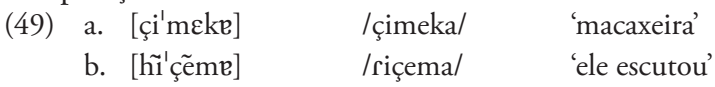

Em posição de onset em sílaba medial:

(50) [tà'çire $]$ /tiçira/ 'aquele' 
Em posição de onset em sílaba final:

(51) ['ffiçi $\quad$ /tfiçi/ 'terra'

Em posição de coda em sílaba inicial:

(52) ['noçtji] /noçitfi/ 'pescoço', 'meu pescoço'

\subsubsection{O Fonema $/ \mathrm{h} /$}

Como dito anteriormente, o fonema fricativo glotal /h/ possui dois alofones: [h] e [h]. O alofone sonoro ocorre em posição de onset, sempre entre vogais. $\mathrm{O}$ alofone surdo ocorre em posição de onset de sílaba inicial e em posição de coda. É importante salienta que /h/ não ocorre diante de /ì/. Exemplos:

[h] fricativo glotal sonoro.

Em posição de onset em sílaba medial:

(53) [i'hitfi] /ihitfi/ 'dente'

Em posição de onset em sílaba final:

(54) ['hõfin $] \quad$ hohi/ 'dia'

[h] fricativo glotal surdo.

Em posição de onset em sílaba inicial:

(55) [ha'wake $]$ /hawaka/ 'ele sobe', 'ele sobe morro acima'

Em posição de onset em sílaba medial:

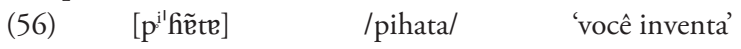

Em posição de coda em sílaba inicial:

(57) ['nihme $] \quad /$ nihĩma/ 'eu tropecei'

Em posição de coda em sílaba medial:

(58) [hõ'wihke] /howihka/ 'longe' 


\subsubsection{O Fonema $/ \mathrm{s} /$}

O fonema aproximante alveolar sonora / / / possui três fones: o fone [r] se realiza em qualquer posição da palavra e com qualquer vogal, mas sempre na posiçáo de onset, mas náo ocorre precedido de consoante nasal, pois neste ambiente ocorre o fone [d]. O fone [l] ocorre em variaçăo livre quando em sílaba final. Exemplos

Em posição de coda em sílaba inicial:

(59) ['rete] /reta/ 'ele viu'

Em posição de onset em sílaba medial:

(60) [pi'rike] /pirika/ 'de manhâ', 'manhâ'

Em posição de onset em sílaba final:

(61) [paj'neri] /pajneri/ 'outra pessoa'

\subsubsection{O Fonema $/ \mathrm{m} /$}

O fonema $/ \mathrm{m} /$ possui só um fone $[\mathrm{m}]$, que ocorre em posição de onset e em posição de coda. Exemplos:

Em posição de onset em sílaba inicial:

(62) [m $\tilde{e}^{\prime} j$ joke $] \quad$ /majoka/ 'latir'

Em posição de onset em sílaba medial:

(63) [çi'meke] /çimeka/ 'macaxeira'

Em posição de onset em sílaba final:

(64) [hĩ'çẽme] /hiçema/ 'ele escutou'

Em posição de coda em sílaba inicial:

(65) [hõm'kahĩ] /homakahi/ 'continuar'

Em posição de coda em sílaba medial:

(66) [he'põmke] /hepomaka/ 'ele se curou da bebedeira' 


\subsubsection{O Fonema $/ \mathbf{n} /$}

O fonema nasal alveolar $/ \mathrm{n} /$ possui só um fone [n], que ocorre na posição de onset e em posição de coda. Exemplos:

Em posição de onset em sílaba inicial:

(67) [na'fitja] /nasitfa/ 'meu cérebro'

Em posição de onset em sílaba medial:

(68) [hina'pəle] /hinapale/ 'direção'

Em posição de onset em sílaba final:

(69) [hĩa'hõni] /hiahoni/ 'e então?'

Em posição de coda em sílaba inicial:

(70) [ts̃̄n'diçi] /tsinfiç̧i/ 'perequitinho'

Em posição de coda em sílaba medial:

(71) [,tsa'pẽntfi] /tsapantfi/ 'bolsa'

\subsubsection{O Fonema /w/}

O fonema aproximante labial $/ \mathrm{w} /$ possui dois alofones: $[\mathrm{w}]$ e $[\beta]$. O alofone fricativo labial ocorre sempre seguido de vogais /i/ e /e/. O alofone [w] ocorre nos demais ambientes, podendo ocorrer em posição de coda ou de onset. Exemplos:

[ $\beta]$ o fricativo labial sonoro

Em posição de onset em sílaba inicial:

(72) [Bi'çitfi] /wiçitji/ 'nossos pés'

Em posição de onset em sílaba medial:

(73) [heßire'puke] /hewirepoka/ 'ele chegou aqui'

Em posição de onset em sílaba final:

(74) ['hewßi] /hewi/ 'aqui' 
[w] aproximante labial sonoro

Em posição de onset em sílaba inicial:

(75) ['wale] /wale/ 'ele'

Em posição de onset em sílaba final:

(76) [kẽ'nawe $] \quad /$ kanawa/ 'canoa'

Em posição de coda em sílaba inicial:

(77) ['Siwre] /Siwrel 'arrepio'

\subsubsection{O Fonema $/ \mathrm{j} /$}

O fonema aproximante palatal /j/ tem um só fone [j], que pode ocorrer seja em posição de onset, seja em posição de coda. Exemplos:

Em posiçấo de onset em sílaba inicial:

(78) [joti'pake] /jotipaka/ 'levantar alguém'

Em posição de onset em sílaba medial:

(79) [ma'joke $] \quad$ /majoka/ 'latir'

Em posição de onset em sílaba final:

(80) ['sejo] 'mas'

Em posição de coda em sílaba inicial:

(81) [maj'tfake] /majtfaka/ 'erro'

Em posição de coda em sílaba final:

(82) ['poj] /poj/ 'boi'

\subsubsection{O Fonema /1/}

O fonema lateral alveolar /1/ possui um único fone [1], que ocorre em posição de onset. Nunca ocorre em início de palavra e nem precedido de consoantes nasais. Exemplos: 
Em posição de onset em sílaba medial:

(83) [ha'litfe] /halitfa/ 'ele tem fe'

Em posição de onset em sílaba final:

(84) [hi'ahle] /hiahile/ 'queixada'

\subsection{Inventário Fonológico das Vogais}

Apresentamos, nesta seção, o inventário dos fonemas vocálicos do Manxineru. O sistema vocálico do Manxineru se configura como semissimétrico, com respeito ao traço arredondado. Nossa análise concorda com a de Matteson (1965), de Hanson (2010) e de Couto (2012) quanto ao inventário fonológico das vogais.

\section{Tabela 2 - Inventário fonológico das vogais do Manxineru}

\begin{tabular}{|c|c|c|c|}
\cline { 2 - 4 } \multicolumn{1}{c|}{} & +Anterior & \multicolumn{2}{c|}{-Anterior } \\
\cline { 2 - 4 } \multicolumn{1}{c|}{} & \multicolumn{2}{c|}{-Arredondado } & +Arredondado \\
\hline +Alto & $\mathrm{i}$ & $\mathrm{i}$ & $\mathrm{o}$ \\
\hline -Alto & $\mathrm{e}$ & $\mathrm{a}$ & \\
\hline
\end{tabular}

Fonte: Couto (2012, p. 62)

\subsubsection{Particularidades Alofônicas das Vogais}

Todas as vogais Manxineru têm variedades fonéticas alongadas e variedades reduzidas, o que nos levou a classificar as suas respectivas realizaçôes fonéticas de monomoráicas, bimoraicas e reduzidas, porém não aprofundaremos esta descrição neste artigo.

\subsubsection{O Fonemalil}

O fonema anterior alto não-arredondado /i/ possui três alofones monomoraicos, dois orais, [i], [I], e um nasal [ĩ].

$\mathrm{O}$ alofone [I] flutua com [i] em posição átona. Exemplos: 
(85) [po'leri] - [po'lesi] /poleri/ 'verde'

O alofone [ĩ] ocorre precedendo consoantes nasais e, frequentemente, seguindo /h/em ambiente nasal.
a. [hiçíi pate]
/riçipata/ 'ele saiu'
b. [ha'tfine]
/hatfina/
'atrás', 'atrás deles'

O alofone [i] ocorre nos demais ambientes. Exemplos:

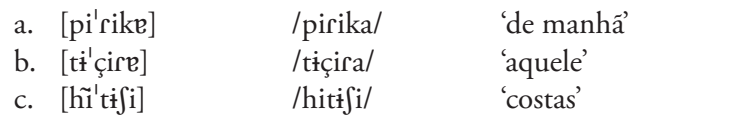

\subsubsection{O Fonemalel}

O fonema /e/ tem três alofones monomoráicos, dois orais $[e],[\varepsilon]$ e

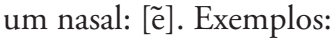

O alofone $[\varepsilon]$ varia livremente com [e] em sílabas tônicas:
a. [pi,se'wate] - [pise'wate]
/pisewata/
'sua unha'
b. [hinni' $\varepsilon k a]$ - [hini'eka]
/hiniekal
'mutum'

O alofone [ẽ] ocorre precedendo consoantes nasais e, frequentemente, seguindo [h]:
(89) a. ['hẽfẽe]
/hehe/ 'sim'
b. [hî'çẽme]
/hiçemal
'ele ouviu'

\subsubsection{O Fonema lal}

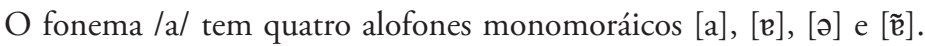
Exemplos:

Os alofones [r] e [ə] variam livremente em sílabas átonas finais:

$$
\text { [,hïma'kate] - [hima'katə] /himakata/ 'ele é capaz' }
$$


O alofone $[\tilde{\mathfrak{e}}]$ ocorre precedendo consoantes nasais e frequentemente seguindo $/ \mathrm{h} /$.

Seguindo /h/:
(91) a. [,hî'pẽne]
/ripana/
'ele morreu', ânus dele'
b. [tfi'tfiph $\tilde{\mathrm{e}}]$
/tfitfipiha/
'fumaça'

O alofone [a] ocorre nos demais ambientes:

(92)
a. [paj'neri]
/pajneri/
'outra gente', 'nação'
b. ['wata]
/watal 'bambu', 'taboca'
c. [hîatu'kape]
/hisatokape/
'ele aparou', 'ele segurou
algo'

\subsubsection{O Fonema lol}

O fonema /o/ possui quatro alofones orais monomoráicos, dois orais [o] e [u], e dois nasais, [õ] e [ũ]. Exemplos:

Os alofones $[\mathrm{o}] \mathrm{e}[\mathrm{u}]$ variam livremente:

$$
\text { [to'kote] [tu'kute] }
$$

/tokota/

'queixo dela'

Os alofones [õ] e [ũ] ocorrem precedendo consoantes nasais ou, frequentemente, seguindo /h/. Estes dois alofones flutuam livremente. Exemplos:
a. [hõ'apra] $~[$ hũ'apra]
/hoapara/
'corujão'
b. ['põ $\left.\tilde{o}^{\mathrm{n}} \mathrm{do}\right]-[$ ['pũn $\mathrm{n}$ do $]$
/ponro/
'centopeia'

Observamos que a palavra para 'boi', que é empréstimo do Português, nunca ocorre com o alofone $[\mathrm{u}]$, e a nossa hipótese é de que não há a flutuação alofônica já que se trata de palavra monossilábica:

$$
\text { ['poj] /poj/ 'boi' }
$$




\subsubsection{O Fonema /i/}

O fonema /ìt possui cinco alofones, dois monomoráicos, um oral [i] e um nasal [ĩ], um bimoráico e um reduzido. Como já mencionado anteriormente, trataremos das vogais reduzidas e alongadas no final desta seção.

O alofone nasal ocorre precedendo consoantes nasais e, frequentemente, seguindo [h]. $\mathrm{O}$ alofone [i] ocorre nos demais ambientes. Exemplos:

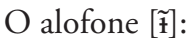

$$
\text { [mõn'tírì] }
$$

/mintìíl

'criança'

O alofone [i] :

(97) a. [só'tiłli $]$

/sotili/ 'pedra'

b. [nnija'nitfi]

/nijanitfi/

'eu me despedi'

\subsubsection{Realizaçôes Bimoraicas}

Quando há, em Manxineru, concatenação morfológica envolvendo certos morfemas, como quando um nome entra em uma relação de posse, combinando-se com prefixos pessoais e sufixo mediador de posse, o acento original se desloca para a sílaba seguinte, alongando a vogal desta sílaba. Exemplos:
a1. [mẽe'tfire]
/matfiral
'macaco preto'
a2. [nomatfi'ra:te]
/nomatsirate/
'meu macaco preto'
b1. [ [̃n'ditfi]
/inlitti/
‘íngua’
b2. ['nõndi]
/nonrit/
'minha língua'

\subsubsection{Realizaçôes Reduzidas das Vogais}

Em Manxineru, vogais reduzidas são encontradas em temas não derivados, como em: 
(99)

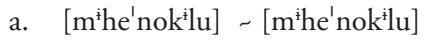
/mihenokilo/
'onça'
b. $\left[\mathrm{t}^{\mathrm{o}} \mathrm{lolo}\right]-\left[\mathrm{t}^{\mathrm{v}} \mathrm{lolo}\right]$
/tololo/
'sapo'

Em temas como esses, em que o acento ocorre na penúltima sílaba, quando há concatenação morfológica envolvendo certos afixos, como o retrospectivo $\{-t\{i\}$, o qual náo provoca deslocamento de acento, a vogal da sílaba pós-tônica final do tema é automaticamente reduzida ou completamente apagada.
(100) a. [,hî-tfika'mapa]
/hitfikamapa/
'estômago parte do corpo'
b. [,hi-tfika' map $\left.^{2}-\mathrm{t} f \mathrm{i}\right]$
/hitfikamapatfi/
'estômago fora do corpo'

\subsubsection{Ensurdecimento Vocálico em Silaba Átona Final}

Verificamos que as vogais monomoraicas $[a, i, \dot{i}, o]$ variam livremente com as surdas [a, $\mathrm{i}$, îo o] em posiçáo átona de sílabas finais. Exemplos:
(101) a. [ratªlatato] - [rat'la'lato]
/ratalalata/
b. [pihẽ 'liți] - [piha'litfi]
/pihalitfi/
'ele queimou'
c. [hẽw' raklı] - [haw'raklt]
/hawrakili/
'teu olho'

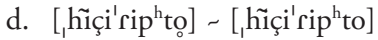
/hiçiripito/
'raio'
'ponta'

\section{Breves Consideraçóes sobre as Adaptaçóes Fonológicas dos Empréstimos em Manxineru}

Verificamos que características fonológicas da adoção de empréstimos do Português pelos Manxineru podem ajudar a entender aspectos da sua fonologia. Em seguida, apresentamos algumas observaçóes sobre as adaptaçóes fonológicas feitas pelos Manxineru com respeito a empréstimos dessa língua:

i) ['set ${ }^{\circ} \mathrm{ro}$ (do Português 'cedro') nos mostra que não existe, em Manxineru, fonema oclusivo sonoro /d/, sendo o /d/ do Português percebido como $/ \mathrm{t} /$.

ii) ['wakə] (do Português 'vaca') confirma o caráter consonantal de /w/, em onset; 
iii) ['poj] (do Português 'boi') reafirma que /b/ é inexistente em Manxineru e que o /j/ pode ocorrer em posição de coda. Esse exemplo mostra ainda que não existe consoante oclusiva bilabial sonora /b/, já que é substituída por $/ \mathrm{p} /$ como ocorre também em [pa'ratə] (do Português 'barata').

iv) [ti'ejru] (do Português 'dinheiro) e [tre'metjo] (do Português 'remédio') afirmam que não há a consoante nasal palatal /n/, que eliminada na fala dos Manxineru.

vi) [wa'riə] (do Português 'farinha') confirma que não há a consoante fricativa labiodental surda /f/.

\section{Consideraçóes finais}

Os fatos expostos neste artigo permitiram-nos analisar e descrever a estrutura fonológica da língua Manxineru, em que não só verificamos 16 fonemas consonantais e cinco vocálicos, mas também pudemos observar outros fenômenos nesta língua (variedade falada no Brasil), como o fonema /h/ não nasal, o qual, diferentemente, não foi tratado dessa forma em outros trabalhos sobre a variedade Piro falada no Peru (MATTESON, 1965; LIN, 1997; SEBASTIÁN, 2006; REBECCA HANSON, 2010). Mostramos ainda que o /l/ e também o / $/$ se realizam foneticamente com /d/, quando precedido de $[\mathrm{n}]$, processo que náo tinha sido descrito por nenhum outro trabalho sobre a variante Manxineru anterior à minha dissertação (COUTO, 2012), aqui já mencionados, sobre o Yine (variedade Piro e variedade Manxineru). Mostramos ainda que não só $/ \mathrm{m} / \mathrm{e} / \mathrm{n} /$ propagam nasalidade, mas também o /h/. Este artigo também evidenciou, mesmo que de forma não exaustiva, algumas adaptaçóes fonológicas quando as palavras são emprestadas do Português ou do Espanhol.

\section{Referências}

CHOMSKY, Noam; HALLE, Morris. The Sound Pattern of English. New York: Harper \& Row, Publisher, 1968.

CLEMEN, G. N.; HUME, Elizabeth V. The Internal Organization of Speech Sounds. In: GOLDSMITH, John A. The Handbook of Phonological Theory. Cambridge, Massachuset: Blackwell, 1995. 
COUTO, Fábio Pereira. Contribuiçóes para a Fonética e Fonologia da Língua Manxineru (Aruák). 2012. Dissertação (Mestrado em Linguística) - Universidade de Brasília, Brasília, 2012, 113 p.

FACUNDES, Sidney da Silva. The language of the Apurina people of Brazil (Maipure/Arawak). 2000. Tese (Doutorado em Linguística). New York: University of New York at Bufallo, 2000, 693 p.

GOLDSMITH, John A. Phonological Theory. In: GOLDSMITH, John A. The Handbook of Phonological Theory. Cambridge, Massachuset: Blackwell, 1995.

LADEFOGED, Peter; MADDIESON, Iam. The Sounds of the World's Languages. Cambridge, Massachuset: Blackwell, 1995.

Vowels and Consonan: an Introduction to the Sounds of Languages. Malden/MA, USA: Blackwell, 2001.

LIN, Yen-Hwei. Syllabic and Moraic Structures in Piro. Phonology, v. 14, n. 3, p. 403-436, 1997.

PIKE, Kenneth. Phonetics a Critical Account of Phonetic Theory and a Techinique for the Pratical Description of Sounds. Ann Arbor. The University of Michigan Press, 1943.

. Phonemics a Techinique for Reducing to Writing. Ann Arbor. The Universite or Michigan Press, [1947] 1971.

RAMIREZ, Henri. Línguas Arawak da Amazônia Setentrional: comparação e descrição. Manaus, Universidade do Amazonas, 2001.

REBECCA HANSON, M. A. A Grammar of Yine(Piro). 2010.Tese (Doutorado em Linguística). Bundoora, Victoria, Australia: 2010, p. 382.

RODRIGUES, Aryon Dall'Igna. Línguas Brasileiras: para o conhecimento das línguas indígenas. 4. ed. São Paulo: Loyola, 2002.

- Silêncio, Nasalidade e Laringalidade em Línguas Indígenas Brasileiras. Letras de Hoje, Porto Alegre, v. 38, n. 4, p. 11-24. 2003.

SEBASTIÁN, Rittma Urquía. Yine: Ilustraciones fonéticas de lenguas ameríndias. In: MARLETT, Stephen A. Lima: SIL International y Universidad, 2006. 
SILVA, Edineide dos Santos. Fonética e Análise Fonológica Preliminar da Língua Manxinéri. 2008. Dissertação (Mestrado em Linguística) Universidade de Brasília, Brasília, 2008.

STORTO, Luciana R.; DEMOLIM, Didier. The phonetics and phonology of South American Languages. In: CAMPBELL, Lyle; GRONDONA, Veronica (Ed.). The indigenous languages of South America: A comprehensive Guide. Berlin/Boston: Lyle Campbell e Verónica Grondona, 2012. p. 331-390.

TRUBETZKOY, N. S. Principles of Phonology. Tradução de Christiane A. M. Baltaxe. Los Angeles: University of California Press, [1939] 1969.

Análise e descriçấo da fonologia segmental do Manxineru Fábio Pereira Couto Recebido em 25/05/2015 Aprovado em 03/08/2015 